\title{
Osteometry of acromion process of adult nigerians: clinical and forensic implications
}

\author{
Abstract \\ Background: This study, morphologically examines the right and the left acromion \\ process of adult Nigerians: its clinical and forensic implications.
}

Objectives: The objectives of the study were to determine the morphometric variables of right and left acromial process, determine the percentage distribution of the types of acromion and types of inferior surfaces of acromion and to compare the values of parameters obtained with that of other populations.

Methods: Data were collected through direct anthropometric measurements of the scapula, obtained from seven institutions in Nigeria which includes, Ahmadu Bello University, University of Port Harcourt, University of Calabar, University of Abuja, Madonna University, Niger Delta University and Nnamdi Azikiwe University. A total number of 214 bones were used for the study. The parameters measured with the aid of vernier caliper, includes Acromial length, breadth, thickness, distance between the tip of acromion process and the tip of coracoid process, distance from the tip of acromion process to the dorsum of the base of coracoid process, distance between the glenoid and acromion process.

Results: The mean values obtained from this study for the right and left scapulae were: $44.62 \pm 5.57 \mathrm{~mm}$ and $43.39 \pm 5.49 \mathrm{~m}, 24.15 \pm 2.36 \mathrm{~mm}$ and $23.69 \pm 2.59 \mathrm{~mm}, 7.90 \pm-$ $1.16 \mathrm{~mm}$ and $7.43 \pm 1.29 \mathrm{~mm}, 39.91 \pm 6.32 \mathrm{~mm}$ and $40.13 \pm 7.62 \mathrm{~mm}, 40.55 \pm 5.57 \mathrm{~mm}$ and $39.53 \pm 5.56 \mathrm{~mm}, 30.16 \pm 4.04 \mathrm{~mm}$ and $30.33 \pm 4.05 \mathrm{~mm}$, respectively. This osteometry showed racial variation. Type II acromion had the highest prevalence and types III and I had the least prevalence in decreasing order.

Conclusion: The study had shown that anthropometry of acromion is important in racial determination, forensic investigations and clinical practices. Thus, recommended to anthropologists, forensic experts and surgeons.

Keywords: morphology, acromion process, adult Nigerians, forensic, anthropology, clavicle, coracoids, scapula, osteometric analysis
Volume 2 Issue I - 2017

\author{
Nweke Cl,' Oladipo GS,' Alabi AS',2 \\ 'Department of Human Anatomy, University of Port Harcourt, \\ Nigeria \\ ${ }^{2}$ Department of Anatomy, University of Ilorin, Nigeria
}

Correspondence: Alabi AS, Department of Human Anatomy, Faculty of Basic Medical Sciences, College of Health Sciences, University of Port Harcourt, Rivers State, Nigeria, Tel +2348030575490, Email dradealabi@gmail.com

Received: October 27, 2016 | Published: February 02, 2017
Abbreviations: MLA, maximum length of acromion; MBA, maximum breadth of acromion; TA, thickness of acromion

\section{Introduction}

There are three processes on the scapula; the spine, the acromion and the coracoids processes. ${ }^{1}$ The term "process" in this context refers to a prominence on a bone. There are two large scapular processes (acromion and coracoid) that extend beyond the margin of the glenoid cavity superior to the head of the humerus. ${ }^{1}$ The morphometry of the scapular showed that the medial angle which is now referred to as the spino vertebral angle, of the right side of the scapula is wider than the left, which has great clinical significance. ${ }^{2}$ The scapular is rather quadrangular instead of being triangular. ${ }^{2}$ The acromion is the larger posterior process having a facet for the lateral end of the clavicle, it is related to varieties of shoulder disorders. ${ }^{3}$ The slope and length of the acromion and the height of the arch are most closely associated with degenerative changes, depending on the type of the acromion. ${ }^{3}$ The morphometric study of the acromion process of the scapular is of great interest in the field of forensic anthropology and in clinical sciences. The morphometry of the acromion process of the scapula is significantly important, as it is implicated in impingement syndrome of the shoulder joint. ${ }^{4}$ The three types of acromion were observed to be: type I (flat), type II (curved) and type III (hooked). In these types of acromion, type III (hooked) acromion was noted to have increase prevalence in rotator cuff tears. ${ }^{4}$ In sexual dimorphism, the males have a greater percentage of type III (hooked) acromion than the females. However the females also have a greater percentage of type I (flat) acromion than the males. In other words, type I is more common in females and type III is more common in males. ${ }^{4}$ Farley et al. ${ }^{5}$ proposed a classification which includes a fourth type of acromion which is concave downward. This classification has not gained much acceptance, mainly owing to the very small incidence of this type of acromion (1.6-13.3\%) and the absence of correlation with rotator cuff pathology. ${ }^{5}$ Natsis et al. ${ }^{6}$ claimed that enthesophytes are significantly more common in the type III acromion and this combination is particularly associated with sub acromial impingement syndrome and rotator cuff tears. In type I and type IV acromia the incidence of enthesophytes was very small and rotator cuff tears were rare. ${ }^{6}$ According to Yukio et al. ${ }^{7}$ the possibility of having a type III acromion is greater as the subject's age increases, allowing for speculation that a hooked form of acromion is a degenerative process. ${ }^{7}$ The aim of this research is to study the osteometric analysis of the acromion process of the scapula stating its clinical and forensic importance in the Nigerian population.

\section{Materials and methods}

A total number of 214 human scapulae (104 from the right and 
110 from the left) were obtained from Anatomical museum of seven Universities in Nigeria namely; Ahmadu Bello University Zaria, University of Port Harcourt, University of Calabar, University of Abuja, Madonna University, Niger Delta University and Nnamdi Azikiwe University. The sample size of this study was based on the availability of already extracted scapulae. Bones which have undergone degenerative changes were exempted from this study as well as scapular with broken acromion or coracoids processes. Standardization of the scapula was done by ensuring it has all the anatomical components as compared with anatomical atlas. The study was carried out on only properly macerated scapular of adults. Standard anthropometric method was used to take the measurements by the use of a sliding vernier calliper with precision or accuracy of $0.01 \mathrm{~mm}$ and recorded in millimetres. The following parameters were measured (Figure1 \& 2). Each measurement was taken twice by a single observer and the average is taken as the standard:

i. Maximum length of acromion (MLA)

ii. Maximum breadth of acromion (MBA)

iii. Thickness of acromion (TA)

iv. The distance between the tip of the acromion process and the tip of the coracoid process (ACD1)

v. The distance from the tip of acromion process to the dorsum of the base of coracoid process (ACD2)

vi. The distance between the supra glenoid tubercle and the tip of the acromion process (AGD).

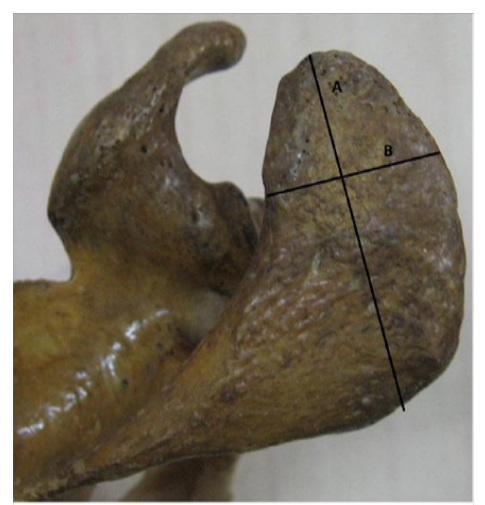

Figure I (A) Measurement of the length of the acromion $L$ and (B) Breadth of the acromion $B$.

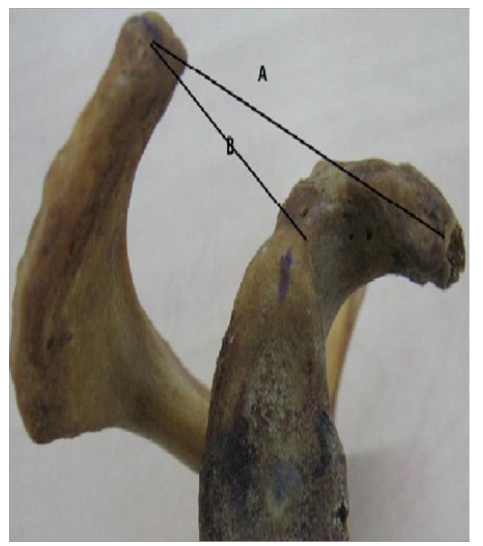

Figure 2 (A) Acromiocoracoid distance $A C D$ and (B) Acromioglenoid distance AGD
The three types of acromion based on shape were classified by observation in to; type I (flat), type II (curved) and type III (hooked) (Figure 3). Data obtained were analyzed using SPSS version 19.0 and results were presented in tables and descriptive statistics like percentage mean and standard deviation and student t-test and z-test were used.
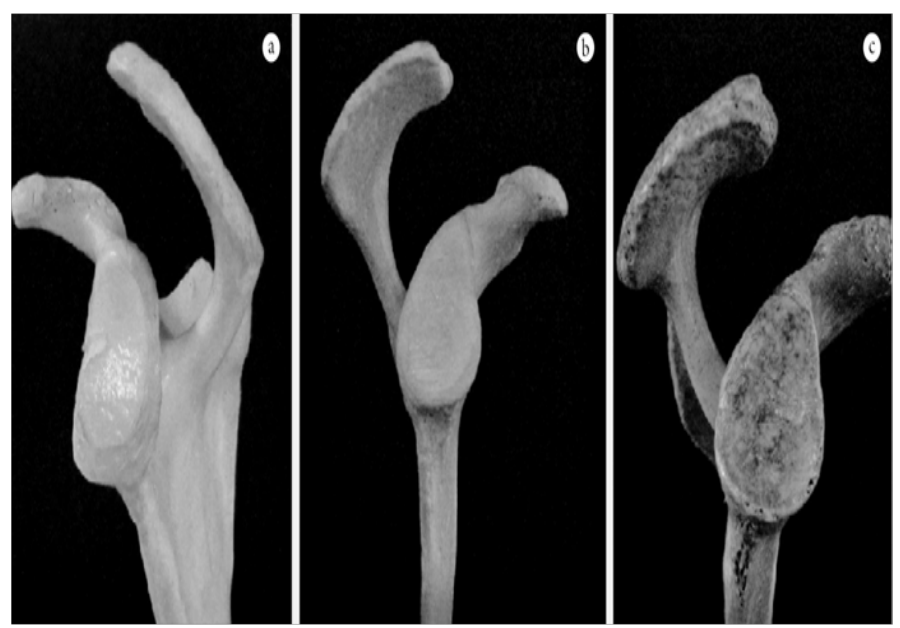

Figure 3 Picture showing types of acromion:

A) Type I acromion- flat

B) Type II acromion- curved and

C) Type III acromion-hooked.

\section{Results}

The results obtained showed the maximum length of the acromion to be $44.62 \pm 5.57 \mathrm{~mm}$ and $43.39 \pm 5.49 \mathrm{~m}$ for the right and left scapula respectively (Table 1) and there was a significant different between the right and the left scapula $(\mathrm{p}<0.05)$ (Table 2). Maximum breadth of acromion was $24.15 \pm 2.36 \mathrm{~mm}$ and $23.69 \pm 2.59 \mathrm{~mm}$ right and left scapula respectively whose difference was statistically significant (Table $1 \& 2$ ). Thickness of acromion for the right was $7.90 \pm-1.16 \mathrm{~mm}$ and the left was $7.43 \pm 1.29 \mathrm{~mm}$ which were significantly different (Table $1 \& 2$ ). The ACD1 for the right and left scapula respectively were $39.91 \pm 6.32 \mathrm{~mm}$ and $40.13 \pm 7.62 \mathrm{~mm}$ but were not significantly different $(\mathrm{p}>0.05)$ (Table $1 \& 2)$. The ACD2 were significantly different $(\mathrm{p}<0.05)$ when the right scapula was compared with that of the left, with their respective values of $40.55 \pm 5.57 \mathrm{~mm}$ and $39.53 \pm 5.56$ (Table $1 \& 2$ ). The AGD for the right and left scapula respectively were $30.16 \pm 4.04 \mathrm{~mm}$ and $30.33 \pm 4.05 \mathrm{~mm}$ as shown in Table $1 \& 2$ and were not significantly different ( $p>0.05$ ). The type II (curved) showed the highest prevalence followed by type III (hooked) and the least was type I (flat) with percentages $77.89 \%, 15.38 \%$ and $6.73 \%$ respectively for the right and $84.55 \%, 8.18 \%$ and $7.27 \%$ respectively for the left (Table 3 ). The acromions with rough surfaces were commoner than the ones with smooth surfaces with $68.27 \%$ and $31.73 \%$ for the right and $71.82 \%$ and $28.18 \%$ for the left respectively (Table 3 ).

In Table 4 there was a significant difference $(p<0.05)$ in the MLA of the Nigerians when compared with those of Indians, ${ }^{8}$ Nepalese $^{9}$ and Chileans. ${ }^{10}$ The MBA was also significantly different when Nigerian were compared with Indians and Nepalese $(p<0.05){ }^{8,9}$ However no significant difference $(\mathrm{p}>0.05)$ was observed when compared with those of Chileans. ${ }^{10}$ The acromion thickness was significantly different $(\mathrm{p}<0.05)$ when those of Nigerians were compared with those of Indians and Chileans. ${ }^{8,10}$ The ACD1 was also significantly different when Nigerian were compared with Indians and Nepalese $(\mathrm{p}<0.05){ }^{8,9}$ 
Conversely no significant difference $(\mathrm{p}>0.05)$ was observed when compared with those of Chileans. ${ }^{10}$ However ACD2 only showed a significantly different $(p<0.05)$ when Nigeria populace is compared Table I Descriptive statistics for the right and left scapulae of Nigerian adults with Indians. ${ }^{8}$ Finally the AGD was significantly different $(\mathrm{p}<0.05)$ in Nigerians when compared with those of Indians, Nepalese and Chileans (Table 4). ${ }^{8-10}$

\begin{tabular}{|c|c|c|c|c|c|c|c|c|}
\hline \multirow{2}{*}{ Variables } & \multicolumn{4}{|c|}{ Right } & \multicolumn{4}{|c|}{ Left } \\
\hline & $\mathbf{N}$ & Mean \pm SD & Max & Min & $\mathbf{N}$ & Mean \pm SD & Max & Min \\
\hline MLA (mm) & 104 & $44.62 \pm 5.57$ & 57.16 & 24.56 & 110 & $43.39 \pm 5.49$ & 54.43 & 29.76 \\
\hline MBA (mm) & 104 & $24.15 \pm 2.36$ & 34.36 & 18.63 & 110 & $23.69 \pm 2.59$ & 31.44 & 18.75 \\
\hline TA (mm) & 104 & $7.90 \pm 1.16$ & 10.52 & 5.03 & 110 & $7.43 \pm 1.27$ & 10.75 & 4.28 \\
\hline $\mathrm{ACDI}(\mathrm{mm})$ & 104 & $39.91 \pm 6.32$ & 58.59 & 25.9 & 110 & $40.13 \pm 7.62$ & 62.11 & 24.38 \\
\hline $\mathrm{ACD} 2(\mathrm{~mm})$ & 104 & $40.55 \pm 5.57$ & 58.26 & 21.63 & 110 & $39.53 \pm 5.56$ & 60.11 & 26.73 \\
\hline AGD $(\mathrm{mm})$ & 104 & $30.16 \pm 4.04$ & 40.21 & 22.4 & 110 & $30.33 \pm 4.05$ & 42.22 & 19.35 \\
\hline
\end{tabular}

Table 2 Results of paired sample test (t-test) between the right and the left acromion process

\begin{tabular}{lllll}
\hline Variables & Degree of freedom $(\mathbf{d f})$ & P-value & T-value & Inference \\
\hline MLA & 103 & 0.087 & 1.73 & Significant \\
MBA & 103 & 0.157 & 1.426 & Significant \\
TA & 103 & 0.002 & 3.17 & Significant \\
ACDI & 103 & 0.94 & 0.075 & Not Significant \\
ACD2 & 103 & 0.178 & 1.356 & Significant \\
AGD & 103 & 0.97 & 0.038 & Not Significant \\
\hline
\end{tabular}

Table 3 Frequency and percentage distributions of types of acromion(TA) and types of acromial surfaces (TS) for the right and the left scapulae

\begin{tabular}{lllll}
\hline Types & TA (Right) & TS (Right) & TA (Left) & TS (Left) \\
\hline Straight or Flat & 7 & - & 8 & - \\
Percentage (\%) & 6.73 & - & 7.27 & - \\
Curved & 81 & - & 93 & - \\
Percentage(\%) & 77.89 & - & 84.55 & - \\
Hooked & 16 & - & 9 & - \\
Percentage (\%) & 15.38 & - & 8.18 & - \\
Rough & - & 71 & - & 79 \\
Percentage (\%) & - & 68.27 & - & 71.82 \\
Smooth & - & 33 & - & 31 \\
Percentage (\%) & - & 31.73 & - & 28.18 \\
\hline
\end{tabular}

Table 4 Comparative table of acromial process morphometry of Nigerian, Indian, Nepalese and Chileans adults

\begin{tabular}{|c|c|c|c|c|c|}
\hline Parameters & Mean士 SD & $\mathbf{Z}(\mathrm{cal})$ & $\mathbf{Z}(\mathrm{tab})$ & Populations & Authors \\
\hline \multirow{4}{*}{ MLA } & $46.4 \pm 0.520$ & 8.81 & 1.645 & *Indians & Jaskaran et al..$^{8}$ \\
\hline & $46.46 \pm 0.470$ & 2.46 & 1.645 & *Nepalese & Mansur et al. ${ }^{9}$ \\
\hline & $69.12 \pm 3.690$ & 2.6 & 1.645 & *Chileans Nigerians & Colipal et al..$^{10}$ \\
\hline & $44.01 \pm 5.530$ & & & & Present study \\
\hline \multirow{4}{*}{ MBA } & $23.40 \pm 0.270$ & 21.39 & 1.645 & *Indians & Jaskaran et al..$^{8}$ \\
\hline & $26.63 \pm 0.220$ & 11.64 & 1.645 & $*$ Nepalese & Mansur et al. ${ }^{9}$ \\
\hline & $25.12 \pm 2.510$ & 0.79 & 1.645 & Chileans Nigerians & Colipal et al..$^{10}$ \\
\hline & $23.93 \pm 2.480$ & & & & Present study \\
\hline
\end{tabular}


Table Continued.

\begin{tabular}{|c|c|c|c|c|c|}
\hline Parameters & Mean \pm SD & $\mathbf{Z}(\mathrm{cal})$ & $\mathbf{Z}(\mathrm{tab})$ & Populations & Authors \\
\hline \multirow{4}{*}{ TA } & $6.60 \pm 0.110$ & 6.76 & 1.645 & *Indians & Jaskaran et al..$^{8}$ \\
\hline & - & - & - & Nepalese & Mansur et al. ${ }^{9}$ \\
\hline & $8.73 \pm 1.870$ & 5.64 & 1.645 & *Chileans Nigerians & Colipal et al..$^{10}$ \\
\hline & $7.67 \pm 1.220$ & & & & Present study \\
\hline \multirow{4}{*}{ ACDI } & $37.10 \pm 0.550$ & 6.34 & 1.645 & *Indians & Jaskaran et al..$^{8}$ \\
\hline & $26.63 \pm 0.500$ & 3.5 & 1.645 & *Nepalese & Mansur et al. ${ }^{9}$ \\
\hline & $39.76 \pm 4.380$ & 0.45 & 1.645 & Chileans Nigerians & Colipal et al..$^{10}$ \\
\hline & $40.02 \pm 6.970$ & & & & Present study \\
\hline \multirow{4}{*}{ ACD2 } & $27.90 \pm 0.440$ & 6.61 & 1.645 & *Indians & Jaskaran et al. ${ }^{8}$ \\
\hline & - & - & - & Nepalese & Mansur et al. ${ }^{9}$ \\
\hline & - & - & - & Chileans Nigerians & Colipal et al..$^{10}$ \\
\hline & $40.04 \pm 5.570$ & & & & Present study \\
\hline \multirow{4}{*}{ AGD } & $26.60 \pm 0.440$ & 7.57 & 1.645 & *Indians & Jaskaran et al. ${ }^{8}$ \\
\hline & $31.00 \pm 3.070$ & 8.47 & 1.645 & *Nepalese & Mansur et al. ${ }^{9}$ \\
\hline & $28.24 \pm 4.810$ & 3.32 & 1.645 & *Chileans Nigerians & Colipal et al. ${ }^{10}$ \\
\hline & $30.25 \pm 4.050$ & & & & Present study \\
\hline
\end{tabular}

\section{Discussion}

The maximum length of the acromion process showed racial variation which is significant in forensic anthropology. This is evidence in the present study as both the right and left scapulae of Nigerians $(44.62 \pm 5.57 \mathrm{~mm}$ and $43.39 \pm 5.49 \mathrm{~mm}$ respectively) varies with the acromial length $46.1 \mathrm{~mm}$ of the Indians reported by Jaskaren et al. ${ }^{8}$ and the Nepalese as reported by Mansur et al. ${ }^{9}$ as $46.46 \pm 5 \mathrm{SDmm}$ and $45.57 \pm 5.21 \mathrm{SDmm}$. Also comparing the MLA, the study of Collipal et al. ${ }^{10}$ on acromion process of adult Chileans as $69.12 \mathrm{~mm}$ and $63.15 \mathrm{~mm}$ for the right and the left respectively, showed a huge variation of the length of acromion process when compared with those of adult Nigerians.

The maximum breadth of acromion of this study agrees with that of Paraskevas et al. ${ }^{3}$ and Collipal et al. ${ }^{10}$ on morphological parameters of the acromion among Greece and Chileans respectively which shows a similar value with that of Nigerian adults. However there was no similarity among the acromial breadth of Nigerian adults, Indians and Nepalese adults as recorded by Jaskaran et al. ${ }^{8}$ and Mansur et al. ${ }^{9}$

The acromial thickness in this study varies with that of the acromial thickness of Indians. ${ }^{8}$ Subsequently the acromion thickness among Nigerians determined in the present study also differs from those of Greece adults. ${ }^{3}$ The distance between the tip of the acromion process and the tip of the coracoid process in this present study disagrees with that of the adult Indians as Jaskaran et al. ${ }^{8}$ recorded $37.5 \mathrm{~mm}$ in general, $37.1 \mathrm{~mm}$ for the right and $37.9 \mathrm{~mm}$ for the left but closely related to the study of Mansur et al. ${ }^{9}$ on adult Nepalese showing $39.03 \pm 6.20 \mathrm{~mm}$ and $39.39 \pm 5.32 \mathrm{~mm}$ for the right and the left scapulae respectively. The distance from the tip of acromion process to the dorsum of the base of coracoid process of Nigerians differs greatly from the work of Jaskaran et al. ${ }^{8}$ among Indian adult scapulae with mean value of
$28.5 \mathrm{~mm}, 29.2 \mathrm{~mm}$ left and $27.9 \mathrm{~mm}$ right. These huge differences could be due to genetic, occupational or environmental factors.

The acromion glenoid distance in this study did not tally with those of Indians, Nepalese and Chileans..$^{8-10}$ These variations with Nigerians are highly significant. The variations of the acromion process observed in the present study with that of other populations like Chileans, Indians, Greece and Nepalese could possibly be as a result of genetic variations, racial differences and environmental factors including occupation and adaptations which may have played a long lasting role in bringing to these differences discovered. According to the Bigliani et al. ${ }^{4}$ classification scheme, the main types of acromial morphology were described: type-I (flat); type-II (curved) and type-III (hooked). They reported the following relative percentages of the three types of acromion process: $8.6 \%$ for type-I, $42.0 \%$ for type- II and $38.6 \%$ for type-III. ${ }^{4}$ This prevalence agrees with the types of acromion in the present study among Nigeria populace. Adult Chileans scapulae as recorded by Collipal et al. ${ }^{10}$ presented $8 \%$ flat, $50 \%$ curved and $42 \%$ hooked which also tally with the present study with type II having the highest frequency followed by type III and type I with the least prevalence. The present study also agrees with Coskun et al. ${ }^{11}$ who also studied the acromial types and discovered $11 \%$ flat, $66 \%$ curved and $23 \%$ hooked. Concurrently Schetino et al. ${ }^{12}$ analyzed acromion's morphology in scapulae of Brazilian human skeleton and observed that distribution of acromial morphology was $5.2 \%$ type I (flat), $57.9 \%$ type II (curved), 36.9\% type III (hooked). However this did not agree with the record of Jaskaran et al. ${ }^{8}$ when they examined the three types of acromion among northern Indian and came out with $22.5 \%$ flat, $38.8 \%$ curved and $38.8 \%$ hooked of the total samples and Paraskevas et al. ${ }^{3}$ also recorded the shape of the acromion among the Greece as type I flat in 23 cases (26.1\%), type II curved in 49 (55.6\%) and as type III hooked in 16 scapulae (18.1\%). 
The possibility of having a type III acromion is greater as the subject's age increases, according to Yukio et al. ${ }^{7}$ this allows some speculation that a hooked form of the acromion is a degenerative process. ${ }^{7}$ The variation in the form of the acromion has been associated with some clinical cases like the sub acromial impingement syndrome, which is defined as a painful process that is caused by the frictions occurring between the inferior surfaces of the anterior acromion, the sub acromial bursa, coracoacromial ligament on the one hand and the rotator cuff on the other. The form, size and above all the excessive anterior prominence of the acromion are the main factors involved in the origin of this injury. ${ }^{13}$ The inferior surfaces of acromion in this study revealed more of rough than smooth surfaces among Nigerians. This is in converse with that reported by Jaskaran et al. ${ }^{8}$ among Indian adults which showed more of smooth surfaces rather than rough surfaces. ${ }^{8}$ However another study carried out among 50 adult Indians by Gupta et al., ${ }^{14}$ showed the inferior surfaces anterior $2 / 3^{\text {rd }}$ were smooth in $(10 \%)$ and rough in $(90 \%) .{ }^{14}$ Paraskevas et al. ${ }^{3}$ found the inferior surface of the anterior third of the acromion process to be smooth in 37 and 72 cases ( $42 \%$ and $55.8 \%)$ respectively and rough in 51 and 57 (57.9\% and $44.2 \%)$ respectively and they all varies slightly from the report of this present study which showed a distinct frequency or prevalence in the favour of the rough surfaces over the smooth surfaces.

\section{Clinical implications}

The morphometric parameters of acromion process would be very helpful in the surgical intervention of the shoulder region. The present study has revealed that in the scapulae of an adult Nigerian, showed no significance difference between the left and the right acromion process in terms of the distance from the tip of the acromion to the tip of the coracoid process and the distance between the supraglenoid tubercle and tip of the acromion process. This is implicated in the case of osteological reconstruction either scapula can be used. However this is only limited to use within a race. It will not be suitable for use from one race to another because of racial variations seen in scapulae. Natsis et al. $^{6}$ claimed that enthesophytes are significantly more common in the type III acromion and this combination is particularly associated with sub acromial impingement syndrome and rotator cuff tears. ${ }^{6}$ The hooked type of acromion, in this study was only $15.38 \%$ on the right and $8.18 \%$ on the left, given reasons for the uncommon cases of rotator curve tears, enthesophytes and acromial impingement in Nigerian population.

The variation in the form of the acromion has been associated with some clinical cases like the sub acromial impingement syndrome, which is defined as a painful process that is caused by the frictions occurring between the inferior surfaces of the anterior acromion, the sub acromial bursa, coracoacromial ligament on the one hand and the rotator cuff on the other. ${ }^{13}$ The form, size and above all the excessive anterior prominence of the acromion are the main factors involved in the origin of this injury. ${ }^{13}$

\section{Forensic implications}

The major challenge for any medico-legal investigator in identifying unknown human remains is the development of biological profile through the identification of race, sex, stature and age. ${ }^{15}$ These biological profiles can dramatically narrow down the pool of possible victim matches and this is very useful in developing country like Nigeria where there are no facilities for definitive DNA test for personality identification. ${ }^{15}$ Our present study showed that acromion has a significant racial variation. This will be useful in medico-legal cases in personality identification such as in cases of mass disaster and crime investigation. Limitations to this study include in ability to classify these bones in to the gender group as the bones were already mixed up together in the various laboratories. The specific ages of these bones cannot be ascertain.

\section{Conclusion}

The morphological study of acromion process of adult Nigerians; clinical and forensic implications, has given an insight into the statistical values and racial variations of right and left acromion process of Nigerian adults' scapulae.This study has also revealed that accurate anthropometric scapular measurement could be of high importance in clinical practice and racial identification in forensic science.

\section{Acknowledgements}

We wish to acknowledge the role played by the Departments of Anatomy of the various Universities visited for making available the scapula bones in their museums for our usage.

\section{Conflict of interest}

The author declares no conflict of interest.

\section{References}

1. Frederic HM, Wiliams CO, Claire WG, et al. Fundamentals of Anatomy and Physiology. 7th ed. 2006. 240 p.

2. Oladipo GS, Aigbogun EO, Akani GL. Angle of the medial border: the spinovertebra angle and its significance. Anat Res Int. 2015;2015:986029.

3. Paraskevas G, Tzaveas A, Papaziogas B, et al. Morphological parameters of the acromion. Folia Morphol (Warsz). 2008;67(4):255-260.

4. Bigliani LU, Ticker JB, Flatow EL, et al. The relationship of acromial architecture to rotator cuff disease. Clin Sports Med. 1991;10(4):823-838.

5. Farley TE, Neumann CH, Steinbach LS, et al. The coracoacromial arch: MR evaluation and correlation with rotator cuff pathology. Skeletal Radiol. 1994;23(8):641-645.

6. Natsis K, Tsikaras P, Totlis T, et al. Correlation between the four types of acromion and the existence of enthesophytes: A study on 423 dried scapulas and review of the literature. Clin Anat. 2007;20(3):267-272.

7. Yukio IR, Duarte BA, Alves Do MF, et al. Acrômio em forma de gancho: uma variação anatômica ou um processo degenerativo? Rev bras ortop. 2005;40:454-463.

8. Singh J, Pahuja K, Agarwal R. Morphometric parameters of the acromion process in adult human scapulae. Indian Journal of Basic \& Applied Medical Research. 2013;2(8):1165-1170.

9. Mansur DI, Khanal K, Haque MK, et al. Morphometry of acromionprocess of human scapulae and its clinical importance amongst Nepalese population. Kathmandu Univ Med J (KUMJ). 2012;10(38):33-36.

10. Collipal E, Silva H, Ortega L, et al. The acromion and his different forms. Int J Morphol. 2010;28(4):1189-1192.

11. Coskun N, Karaali K, Cevikol C, et al. Anatomical basics and variations of the scapula in Turkish adults. Saudi Med J. 2006;27(9):1320-1325.

12. Schetino LPL, Sousa Junior RR, Amâncio GPO, et al. Anatomical variations of acromions in brazilianadult'sscapulas. J Morphol Sci. 2013;30(2):98-102. 
13. Neer CS. Anterior acromioplasty for the chronic impingement syndrome in the shoulder. J Bone Joint Surg Am. 1972;54(1):41-50.

14. Gupta C, Priya A, Guruprasad Kalthur S, et al. A morphometric study of acromion process of scapula and its clinical significance. CHRISMED J Health Res. 2014;1(3):164-169.
15. Ahmed AA. Estimation of stature using lower limb measurements in Sudanese Arabs. J Forensic Leg Med. 2013;20(5):483-488. 